\title{
EVALUATION OF NASOPALATINE CANAL USING CONE BEAM COMPUTED TOMOGRAPHY - A RETROSPECTIVE STUDY
}

\section{Dental Science}

\section{Dr. K Saraswathi} Gopal

\section{Dr. Priyam Kapoor*}

MDS, Professor and Head of the Department, Faculty of Dentistry, Department of Oral Medicine and Radiology, Meenakshi Academy of Higher Education and Research University, Chennai, Tamil Nadu, India

III year Postgraduate, Department of Oral Medicine and Radiology, Meenakshi Ammal Dental College, Chennai, Tamil Nadu, India *Corresponding Author

\begin{abstract}
Background: Implantology is a very significant branch of dentistry that deals with the rehabilitation of edentulous patients. Thus, knowledge of anatomical variations of related neurovascular structures such as the nasopalatine canal is essential.

Aim: The aim of study was to determine the form, length, and diameter of the nasopalatine canal using CBCT.

Materials and Methods: In this retrospective study, images were archived from CBCT unit and visualized using Romexis software. The nasopalatine canals of 50 patients between the age range of 18-59years were analyzed. The shape of the nasopalatine canal, length of the nasopalatine canal and the diameter of incisive foramen were assessed in sagittal and coronal section. The width of labial and palatal alveolar bone around the canal and inclination of the nasopalatine canal to hard palate were evaluated. Statistics: (1) if there is any relation between the gender and the assessed parameters (2) if there is any relation between edentulous and partially edentulous patients with the assessed parameters.

Results: The most common shape of the nasopalatine canal was cylindrical. The average length of the nasopalatine canal was $12.14 \pm 2.41 \mathrm{~mm}$ and the average diameter of incisive foramen $3.45 \pm 0.84 \mathrm{~mm}$ anteroposteriorly and $3.77 \pm 0.94 \mathrm{~mm}$ mediolaterally. The average inclination of the nasopalatine canal to hard palate was $119.93 \pm 9.73^{\circ}$

Conclusion: This study highlights the variations seen in the nasopalatine canal. The close vicinity of nasopalatine canal and implant can lead to sensory disturbances and damage of the tissues. Thus, a thorough knowledge before the surgical - implant procedure using cone beam computed tomography seems beneficial.
\end{abstract}

\section{KEYWORDS}

Imaging, Implantology, Nasopalatine canal, Oral Surgical Procedure - Cone Beam Computed Tomography

\section{INTRODUCTION}

The nasopalatine canal also called incisive canal or anterior palatine canal, has been described as a canal, connecting the hard palate to the nasal floor. It is located in the middle of the hard palate just posterior to the roots of maxillary central incisors. It has two openings: orally, the incisive foramen, which is located underneath the incisive papilla, and in the nasal cavity its opening is known as foramina of Stenson. The nasopalatine nerve, the terminal branch of descending nasopalatine artery, fibrous connective tissue, fat, and small salivary glands are the contents of the nasopalatne canal. ${ }^{1,2}$

Maxillary anterior region is the most common region prone to trauma and tooth loss. Thus, attention should be given to the resorption of the alveolar bone following the loss of incisors. ${ }^{3}$ Now-a-days, dental implant has emerged as new treatment modality for edentulous areas. Since it has ability to restore the functional and esthetic need of patients, it is considered as the best method of choice for replacing missing teeth. The success rate of dental implant in maxillary anterior region depends on factors such as the location and angle of implant. The adequate distance between the implant and vital anatomical structures. ${ }^{4}$ Evaluating the size and morphology of the nasopalatine canal before surgical intervention of implant surgery is very important. A thorough assessment of the position of the canal and available cortical bone around the canal using CBCT prior to implant insertion procedure will be highly beneficial for the surgeon.

Failure in implantology has been frequently encountered that require implant removal and tissue augmentation. Implant contact with neurovascular tissue such as the nasopalatine canal might result in the loss of osseointegration or development of sensory disturbances. ${ }^{6,7,8} \mathrm{In}$ order to minimize complications following implant placement in the incisor area, proper image of the incisive canal and foramen before implant placement is highly important since it can help determine the morphology and position of the canal in relation to the surrounding structures. The various two-dimensional imaging modalities including intraoral and panoramic radiograph have been used. In the recent years, precise three-dimensional assessment before dental implant placement has increased dramatically. ${ }^{9,10}$ However, cone-beam computed tomography has been proposed as a valuable threedimensional imaging technique in assessing the three-dimensional configuration of nasopalatine canal, its position in relation to the surrounding structures and available alveolar bone. CBCT enables us

to carefully plan the implant, selecting the implant site and relationship with important anatomical structures such as nasopalatine canal. ${ }^{1}$

\section{AIMAND OBJECTIVES}

The aim of this study is to assess the three-dimensional morphology and dimensions of nasopalatine canal and incisive foramen using CBCT data archives from the department of oral and maxillofacial radiology.

The objectives of this study are as follows:

1. To assess the shape of nasopalatine canal

2. To measure the length of nasopalatine canal

3. To measure the incisive foramen diameter anterioposteriorly and mediolaterally

4. To measure the labial cortical plate to nasopalatine canal at palatal, middle and nasal level

5. To measure the palatal cortical plate to nasopalatine canal at palatal, middle and nasal level

6. To measure the inclination of nasopalatine canal to hard palate

\section{MATERIALSAND METHOD}

In this retrospective study, 50 CBCT scans were archived from the CBCT unit (Planmeca, Mid Proface, Helsinki, Finland) and visualized in Romexis software. Fifty CBCT images of 27 dentulous and 23 partially edentulous patients with an age ranging from 18 to 59 years were included in the study. The study was approved by the ethical committee of the institution. The board of ethics was aware that it was a retrospective study and the study was undertaken using patient's records/data/radiographs. This software enables meticulous dimensional measurements of following parameters: shape of nasopalatine canal, length of nasopalatine canal, incisive foramen anteroposterior and mediolateral diameter, inclination of nasopalatine canal to hard palate and the width of labial and palatal cortical bone around the nasopalatine canal. The CBCT scans were evaluated in coronal and sagittal section. The CBCT images were visualized in sagittal and coronal section with a slice thickness of $1 \mathrm{~mm}$. The CBCT image that showed the complete nasopalatine canal with the oral and nasal opening accurately was selected for measurements. The measurements were performed digitally by the tools provided within the romexis software. The CBCT images were evaluated by a single observer at two different intervals of time. The average of the measurements was taken as the final value. 


\section{Inclusion criteria:}

- $\quad$ CBCT scans with maxillary anterior region

- $\quad$ CBCT scans of dentulous and partially edentulous patients i.e. any one of the central incisors missing

- Patients above 18 years of age

\section{Exclusion criteria:}

- Poor quality CBCT images

- Abnormalities of maxilla

- Fracture in maxillary anterior region

- Presence of radiolucent or radiopaque lesions

- Impacted teeth in area of interest

- Presence of orthodontic appliances

\section{CBCT Analysis:}

1 Shape of the nasopalatine canal: the following classification based on the shape seen on the sagittal plane.

a. Cylindrical: when the labial and palatal walls of the canal are parallel.

b. Funnel: when the anteroposterior dimension of the canal increased from the nasal fossa to the hard palate.

c. Hourglass: when the anteroposterior dimension is narrowest at the mid-level of the canal compared to the dimensions at the nasal and palatal levels.

d. Spindle: when the anteroposterior dimension is widest at the midlevel of the canal compared to the dimensions at the nasal and palatal levels.

2 Length of the nasopalatine canal: The measurement of the mean length of the nasopalatine canal was made in the sagittal plane from the oral opening to the nasal opening of the canal in millimeters. Figure 2 depicts the measurement

3 Incisive foramen diameter: it was also calculated in the sagittal plane by measuring the anteroposterior distance of the oral entrance of the nasopalatine canal and in the coronal plane by measuring the mediolateral distance of the oral entrance of nasopalatine canal. Figure 2 and 3 depicts the measurement

4 Inclination of the nasopalatine canal to the hard palate: it was calculated using an angle measuring tool in the software. A line drawn in the middle of the oral and nasal openings of the nasopalatine canal and another in the hard palate. Figure 1 depicts the measurement

5 Width of Labial cortical plate: the distance between the anterior wall of the nasopalatine canal and the labial cortex measured at palatal, middle and nasal level. Figure 1 depicts the measurement

6 Width of Palatal cortical plate: the distance between the posterior wall of nasopalatine canal and the palatal cortex measured at palatal, middle and nasal level Figure 1 depicts the measurement

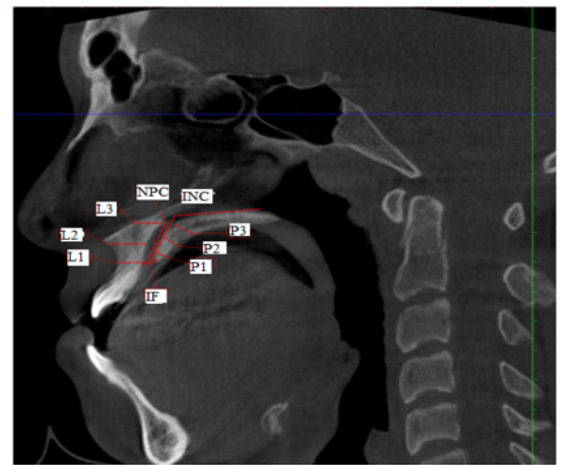

Figure 3: Measurements in coronal section, incisive canal mediolateral diameter (INF)

Figure 2: Measurements in sagittal section, length of nasopalatine canal (NPC), incisive canal diameter anterioposterior (IF), inclination to hard palate (INC), width of labial cortical bone at palatal (L1), middle (L2) and nasal (L3) level, width of palatal cortical bone at palatal (P1), middle (P2) and nasal (P3) level

\section{STATISTICALANALYSIS}

Descriptive statistics of age and gender of the patients for the shape of nasopalatine canal, its length, inclination related to the hard palate and the incisive foramen diameter, were done. All statistical analyses were performed using SPSS software. P-value $<0.05$ was considered statistically significant. Statistical analysis was done to determine: (a) if there is a relation between dentulous and partially edentulous patients with assessed nasopalatine canal parameters (b) if there is difference between gender considering nasopalatine canal length, inclination to hard palate, width of labial and palatal alveolar bone and the incisive foramen diameter.

Pearson's correlation coefficient test was used to assess the correlation between dentulous and partially edentulous groups, regarding nasopalatine canal length, incisive foramen diameter, inclination of nasopalatine canal with hard palate and width of labial and palatal alveolar bone. The Independent samples T-test was conducted to evaluate the comparison between males and females of the nasopalatine canal length, incisive foramen diameter, inclination of nasopalatine canal with hard palate and width of labial and palatal alveolar bone.

\section{RESULTS}

In the 50 CBCT scans, there were 29 males and 21 females. The most common shape of nasopalatine canal was cylindrical followed by funnel, hourglass and spindle. The mean length of nasopalatine canal was $12.14 \pm 2.41 \mathrm{~mm}$, minimum length $11.46 \mathrm{~mm}$ and maximum 12.83 $\mathrm{mm}$. The mean incisive foramen anteroposterior diameter was $3.45 \pm 0.84 \mathrm{~mm}$, minimum $3.21 \mathrm{~mm}$ and maximum $3.69 \mathrm{~mm}$. The mean incisive foramen mediolateral diameter was $3.77 \pm 0.94 \mathrm{~mm}$, minimum $3.5 \mathrm{~mm}$ and maximum $4.04 \mathrm{~mm}$. The mean inclination of nasopalatine canal with hard palate was $119.93 \pm 9.73$ degree, minimum 117.16 degree and maximum 122.69 degree. The mean labial cortical bone at palatal, middle and nasal level was $6.22 \pm 1.73 \mathrm{~mm}, 6.9 \pm 1.87 \mathrm{~mm}$ and $13.48 \pm 41.82 \mathrm{~mm}$ respectively. The mean palatal cortical bone at palatal, middle and nasal level was $2.87 \pm 0.78 \mathrm{~mm}, 4.48 \pm 1.06 \mathrm{~mm}$ and $6.22 \pm 1.67 \mathrm{~mm}$ respectively. The descriptive statistics are given in Table 1 .

\begin{tabular}{|l|c|c|c|}
\hline \multicolumn{3}{|c|}{ DESCRIPTIVE TABLE } \\
\hline \multicolumn{1}{|c|}{ PARAMETER } & MEAN \pm SD & \multicolumn{2}{c|}{ CI } \\
\cline { 3 - 4 } & & LOWER & UPPER \\
\hline Age & $33.52 \pm 10.37$ & 30.572 & 36.48 \\
\hline Nasopalatine canal & $12.14 \pm 2.41$ & 11.46 & 12.83 \\
\hline Incisive foramen AP & $3.45 \pm 0.84$ & 3.21 & 3.69 \\
\hline Incisive foramen ML & $3.77 \pm 0.94$ & 3.5 & 4.04 \\
\hline $\begin{array}{l}\text { Labial cortical bone - Palatal } \\
\text { level }\end{array}$ & $6.22 \pm 1.73$ & 5.72 & 6.71 \\
\hline $\begin{array}{l}\text { Labial cortical bone - Middle } \\
\text { level }\end{array}$ & $6.9 \pm 1.87$ & 6.36 & 7.43 \\
\hline $\begin{array}{l}\text { Labial cortical bone - Nasal } \\
\text { level }\end{array}$ & $13.48 \pm 41.82$ & 1.6 & 25.37 \\
\hline $\begin{array}{l}\text { Palatal cortical bone - Palatal } \\
\text { level }\end{array}$ & $2.87 \pm 0.78$ & 2.64 & 3.09 \\
\hline $\begin{array}{l}\text { Palatal cortical bone - Middle } \\
\text { level }\end{array}$ & $4.48 \pm 1.06$ & 4.18 & 4.8 \\
\hline $\begin{array}{l}\text { Palatal cortical bone - Nasal } \\
\text { level }\end{array}$ & $6.22 \pm 1.67$ & 5.75 & 6.7 \\
\hline $\begin{array}{l}\text { Inclination of nasopalatine } \\
\text { canal to hard palate }\end{array}$ & $119.93 \pm 9.73$ & 117.16 & 122.69 \\
\hline
\end{tabular}

Table 1: Mean, standard deviation (SD) and confidence interval (CI) of age, nasopalatine canal length, incisive foramen anteroposterior (AP) diameter, incisive foramen mediolateral (ML) diameter, labial cortical bone and palatal cortical bone at palatal, middle and nasal level and inclination of nasopalatine canal to hard palate

Pearson's correlation coefficient test suggested that incisive foramen mediolateral diameter and inclination of nasopalatine canal with hard palate was significantly different in dentulous and partially edentulous patients. There was no statistically significant relationship between dentulous and partially edentulous patients regarding other assessed parameters. The results of pearson's correlation coefficient test are depicted in Table 2 .

Table 2: Mean, standard deviation and p-value in dentulous and partially edentulous patients

\begin{tabular}{|l|l|l|l|}
\hline \multicolumn{4}{|c|}{ Inferential Table 2: Group wise comparsion } \\
\hline Parameter & Dentulous & Edentulous & p-value \\
\hline Nasopalatine canal & $11.87 \pm 2.54$ & $12.43 \pm 2.26$ & 0.387 \\
\hline Incisive foramen AP & $3.43 \pm 0.69$ & $3.48 \pm 1.01$ & 0.851 \\
\hline Incisive foramen ML & $3.46 \pm 0.78$ & $4.13 \pm 0.99$ & 0.012 \\
\hline
\end{tabular}




\begin{tabular}{|l|l|l|l|}
\hline $\begin{array}{l}\text { Labial cortical bone - Palatal } \\
\text { level }\end{array}$ & $6.35 \pm 1.60$ & $6.06 \pm 1.91$ & 0.561 \\
\hline $\begin{array}{l}\text { Labial cortical bone - Middle } \\
\text { level }\end{array}$ & $6.95 \pm 1.97$ & $6.83 \pm 1.79$ & 0.823 \\
\hline $\begin{array}{l}\text { Labial cortical bone - Nasal } \\
\text { level }\end{array}$ & $7.38 \pm 2.30$ & $7.1 \pm 3.59$ & 0.553 \\
\hline $\begin{array}{l}\text { Palatal cortical bone - } \\
\text { Palatal level }\end{array}$ & $2.84 \pm 0.92$ & $2.90 \pm 0.60$ & 0.784 \\
\hline $\begin{array}{l}\text { Palatal cortical bone - Middle } \\
\text { level }\end{array}$ & $4.30 \pm 1.10$ & $4.69 \pm 0.99$ & 0.197 \\
\hline $\begin{array}{l}\text { Palatal cortical bone - Nasal } \\
\text { level }\end{array}$ & $6.27 \pm 1.76$ & $6.17 \pm 1.60$ & 0.838 \\
\hline $\begin{array}{l}\text { Inclination of nasopalatine } \\
\text { canal to hard palate }\end{array}$ & $122.42 \pm 10.07$ & $117 \pm 8.63$ & 0.046 \\
\hline
\end{tabular}

The Independent samples T-test revealed that width of palatal cortical bone was significantly lower in females than males at all the three levels. The mean length of nasopalatine canal, incisive foramen diameter, width of labial and palatal cortical bone was shorter in females than in males but not statistically significant. The results of independent samples t-test are depicted in Table 3.

Table 3: Mean, standard deviation and p-value in males and females

\begin{tabular}{|l|l|l|l|}
\hline \multicolumn{4}{|c|}{ Inferential Table 1: Gender wise comparsion } \\
\hline Parameter & Male & Female & p-value \\
\hline Nasopalatine canal & $12.70 \pm 2.23$ & $11.38 \pm 2.50$ & 0.62 \\
\hline Incisive foramen AP & $3.58 \pm 0.94$ & $3.27 \pm 0.66$ & 0.17 \\
\hline Incisive foramen ML & $3.81 \pm 0.97$ & $3.72 \pm 0.90$ & 0.73 \\
\hline $\begin{array}{l}\text { Labial cortical bone - Palatal } \\
\text { level }\end{array}$ & $6.24 \pm 1.83$ & $6.19 \pm 1.64$ & 0.92 \\
\hline $\begin{array}{l}\text { Labial cortical bone - Middle } \\
\text { level }\end{array}$ & $6.99 \pm 1.74$ & $6.77 \pm 2.08$ & 0.69 \\
\hline $\begin{array}{l}\text { Labial cortical bone - Nasal } \\
\text { level }\end{array}$ & $7.2 \pm 2.65$ & $8 \pm 3.07$ & 0.227 \\
\hline $\begin{array}{l}\text { Palatal cortical bone - } \\
\text { Palatal level }\end{array}$ & $3.15 \pm 0.77$ & $2.49 \pm 0.63$ & 0.002 \\
\hline $\begin{array}{l}\text { Palatal cortical bone - Middle } \\
\text { level }\end{array}$ & $4.83 \pm 0.98$ & $4.00 \pm 0.99$ & 0.006 \\
\hline $\begin{array}{l}\text { Palatal cortical bone - Nasal } \\
\text { level }\end{array}$ & $6.82 \pm 1.53$ & $5.40 \pm 1.52$ & 0.002 \\
\hline $\begin{array}{l}\text { Inclination of nasopalatine } \\
\text { canal to hard palate }\end{array}$ & $117.94 \pm 10.37$ & $122.67 \pm 8.23$ & 0.079 \\
\hline
\end{tabular}

\section{DISCUSSION}

The replacement and restoration of maxillary anterior teeth using dental implants is a viable treatment option and rapidly advancing field of dentistry. But it has been a challenging task for the dental surgeon due to its aesthetic concern, functional requirements and close proximity to vital anatomical structures such as nasopalatine canal and incisive foramen. Successful implant treatment to replace the missing teeth in anterior maxilla requires precise preoperative planning with appropriate radiological investigations. The nasopalatine canal have been studied in great detail by various researchers in different ways using dry skulls and imaging technology either two-dimensional or three-dimensional radiography such as CBCT.

In the present study, we evaluated the nasopalatine canal using CBCT technology in a Chennai population. In our sample, the form of the canal was variable. The cylindrical and funnel-shaped canals were the most detected followed by the hourglass-shaped and the spindleshaped which was the rarest. These results are consistent with the results reported by some of the earlier studies conducted by Nasseh et al. (2017); Kajan et al. (2015); Tozum et al. (2012); Mardinger et al. (2008). ${ }_{1,12,13,14}$ But in one study Mraiwa et al. (2004) assessed nasopalatine canal in 2D and 3D images which showed results different from the present study. ${ }^{15}$ According to their study, Y-shaped canal was the most common which corresponds to funnel in the present study. It can be explained by racial difference and limited sample size compared to the present study.

The mean length of nasopalatine canal in the present study was higher than that reported by some earlier research by Nasseh et al. (2017); Bornstein et al. (2011); Tozum et al. (2012). ${ }^{1,13,16}$ On contrary, the nasopalatine canal length in the present study was similar to that reported in two studies by Kajan et al. (2015); Salemi et al. (2016). $[3,12]$ In the present study, the length of nasopalatine canal was shorter in females than in males but it was not statistically significant. On the other hand, few researchers: Kajan et al. (2015); Tozum et al. (2012); Nasseh et al (2017) reported that the length of nasopalatine canal was significantly higher in males than females. ${ }^{1,12,13}$ The length of nasopalatine canal didn't show statistical significant difference between the dentulous and partially edentulous groups.

In our study, the incisive foramen anteriorposterior diameter ranged from 3.21 to 3.69 which was lower than that reported in three of the studies in the past by Panjnoush et al. (2016); Nasseh et al. (2017); Bornstein et al. (2011). ${ }^{1,11,16}$ There was no significant difference between males and females in our study similar to that reported by Kajan et al. (2015); Nasseh et al. (2017); Bornstein et al. (2011). $[1,12,16]$ But only in one study, Panjnoush et al. (2016) revealed that females have shorter incisive foramen diameter in sagittal section compared to males." There was no significant difference between incisive foramen anteriorposterior diameter between the two dentulous and partially edentulous groups but incisive foramen mediolateral diameter was significantly higher in partially edentulous patients compared to dentulous patients.

The width of palatal cortical bone at the three different levels was significantly lower in females compared to males in the present study. There was no significant difference in width of labial cortical bone at the three different levels in between males and females. In one study conducted by Kajan et al. (2015) on Iranian population, the bone width in buccal and palatal sides of canal at three different levels didn't show significant difference between males and females except on palatal side at middle level. ${ }^{12}$ On the other hand, studies carried out in the population of Switzerland, Turkey, Spain and Saudi Arabia by Bornstein et al. (2011); Tozum et al. (2012) reported that dimension of buccal bone plate was significantly higher in males than females. ${ }^{13,16}$ The difference may be due to ethnicity variation or the difference in mean age in our study.

The inclination of nasopalatine canal to hard palate showed a range of 117.16 to 122.69 degrees. There was a significant difference between dentulous and patially edentulous patients with a $p$ value 0.046 . The mean inclination was lower in patially edentulous than dentulous patients. Only in one study, Panjnoush et al. (2016) reported no statistical significance between the two groups regarding inclination to palatal bone.

Renton et al. reported that only one in ten patients underwent a 3D imaging and computed tomography before the implant placement. There have been reported cases in literature of nasopalatine canal cyst associated with dental implants. The published data have emphasized on preoperative $3 \mathrm{D}$ planning using cone beam computed tomography prior to implant placement procedures to avoid complications. ${ }^{18,1}$ Sukhegawa et al. have suggested that trauma to the nasopalatine canal during the surgical procedure of implant placement can lead to cyst development. ${ }^{18}$ Casado et al. reported that the implants had to be removed along with the lesion. But in some instances when the implants are not mobile or the lesion doesn't surround other teeth/implants, they can be left behind. ${ }^{19}$ Jacob et al. mentioned that after extraction in maxillary central incisor area the canal gets enlarged by $1.8 \mathrm{~mm}$. So, the chances of trauma to the canal increases and can lead to cyst initiation. ${ }^{20}$ Balshi et al. conducted a long term follow up study on stability of resected implants after surgery. He concluded that the size of radiolucency reduced significantly following the implant resection. ${ }^{2}$

Finally, in our study, some limiting factors exist such as: (a) the small number of CBCT scans assessed making further studies on a larger sample essential to be performed in order to have more precise findings; (b) time elapsed since the loss of central incisors not taken under consideration and (C) (lack of data available) we did no examine the CBCT scans with both the central incisors missing, something that would be interesting for future studies.

\section{CONCLUSION}

This study highlighted the anatomic variability of the nasopalatine canal in relation to several parameters. Within the limits of this study, we conclude that, the form of the nasopalatine canals variable, predominantly cylindrical or funnel shaped. The width of palatal bone at three different levels was shorter in females than males. The incisive foramen mediolateral diameter and nasopalatine canal inclination to hard palate showed significant difference in dentulous and partially 
edentulous groups. The length of canal, incisive foramen anterioposterior diameter and labial cortical bone didn't reveal significant difference in the dentulous and partially edentulous groups and between genders.

\section{REFERENCES}

1. Nasseh I, Aoun G, Sokhn S. Assessment of the nasopalatine canal: An anatomical study. Acta Informatica Medica. 2017 Mar;25(1):34

2. Fernández-Alonso A, Suárez-Quintanilla JA, Muinelo-Lorenzo J, Varela-Mallou J, Chamosa ES, Suárez-Cunqueiro MM. Critical anatomic region of nasopalatine canal based on tridimensional analysis: cone beam computed tomography. Scientific reports. 2015 Aug 6;5:12568.

3. Salemi F, Atarbashi Moghadam F, Shakibai Z, Farhadian M. Three-dimensional assessment of the nasopalatine canal and the surrounding bone using cone-beam computed tomography. Journal of Periodontology \& Implant Dentistry. 2016 Jan $5 ; 8(1): 1-7$.

4. Rao JB, Tatuskar P, Pulla A, Kumar N, Patil SC, Tiwari I. Radiographic Assessment of Anatomy of Nasopalatine Canal for Dental Implant Placement: A Cone Beam Computed Tomographic Study. The journal of contemporary dental practice. 2018 Mar;19(3):301-5.

5. Mishra R, Thimmarasa VB, Jaju PP, Mishra R, Shrivastava A. Influence of gender and age on nasopalatine canal: A cone-beam computed tomography study. Journal of Dental age on nasopalatine canal: A

6. Thakur AR, Burde K, Guttal K, Naikmasur VG. Anatomy and morphology of the nasopalatine canal using cone-beam computed tomography. Imaging science in dentistry. 2013 Dec 1;43(4):273-8

7. Al-Amery SM, Nambiar P, Jamaludin M, John J, Ngeow WC. Cone beam computed tomography assessment of the maxillary incisive canal and foramen: considerations of anatomical variations when placing immediate implants. PLoS One. $2015 \mathrm{Feb}$ 13;10(2):e0117251

8. Safi Y, Moshfeghi M, Rahimian S, Kheirkhahi M, Manouchehri ME. Assessment of nasopalatine canal anatomic variations using cone beam computed tomography in a group of Iranian population. Iranian Journal of Radiology. 2017;14(1)

9. Fukuda M, Matsunaga S, Odaka K, Oomine Y, Kasahara M, Yamamoto M, Abe S. Three-dimensional analysis of incisive canals in human dentulous and edentulous maxillary bones. International journal of implant dentistry. $2015 \mathrm{Dec} ; 1(1): 12$

10. Song WC, Jo DI, Lee JY, Kim JN, Hur MS, Hu KS, Kim HJ, Shin C, Koh KS. Microanatomy of the incisive canal using three-dimensional reconstruction of microCT images: an ex vivo study. Oral Surgery, Oral Medicine, Oral Pathology, Oral Radiology, and Endodontology. 2009 Oct 1;108(4):583-90.

11. Panjnoush M, Norouzi $\mathrm{H}$, Kheirandish $\mathrm{Y}$, Shamshiri AR, Mofidi N. Evaluation of morphology and anatomical measurement of nasopalatine canal using cone beam computed tomography Journal of dentistry (Tehran, Iran). 2016 Aug;13(4):287.

12. Kajan ZD, Kia J, Motevasseli S, Rezaian SR. Evaluation of the nasopalatine canal with cone-beam computed tomography in an Iranian population. Dental research journal. $2015 \mathrm{Jan} ; 12(1): 14$

13. Tözüm TF, Güncü GN, Yıldırım YD, Yılmaz HG, Galindo-Moreno P, Velasco-Torres M, Al-Hezaimi K, Al-Sadhan R, Karabulut E, Wang HL. Evaluation of maxillary incisive canal characteristics related to dental implant treatment with computerized tomography: a clinical multicenter study. Journal of periodontology. 2012 Mar;83(3):337-43

14. Mardinger O, Namani-Sadan N, Chaushu G, Schwartz-Arad D. Morphologic changes of the nasopalatine canal related to dental implantation: a radiologic study in different degrees of absorbed maxillae. Journal of periodontology. $2008 \mathrm{Sep} ; 79(9): 1659-62$.

15. Mraiwa N, Jacobs R, Van Cleynenbreugel J, Sanderink G, Schutyser F, Suetens P, van Steenberghe D, Quirynen M. The nasopalatine canal revisited using 2D and 3D CT imaging. Dentomaxillofacial Radiology. 2004 Nov;33(6):396-402.

16. Bornstein MM, Balsiger R, Sendi P, Von Arx T. Morphology of the nasopalatine canal and dental implant surgery: a radiographic analysis of 100 consecutive patients using limited cone-beam computed tomography. Clinical oral implants research. 2011 Mar;22(3):295-301.

17. Renton T, Dawood A, Shah A, Searson L, Yilmaz Z. Post-implant neuropathy of the trigeminal nerve. A case series. BrDent J 2012:212: E17.

18. Sukegawa S, Kanno T, KawaiH, Takebe Y, ShibataA, Takahashi Y, Nagatsuka H, Furuki Y. Nasopalatine duct cyst associated with dental implant treatment: A case report. Oral and Maxillofacial Surgery Cases. 2015 Sep 1;1(3):38-41.

19. Casado PL, Donner M, Pascarelli B, Derocy C, Duarte ME, Barboza EP. Immediate dental implant failure associated with nasopalatine duct cyst. Implant Dent. 2008; $17: 169-75$

20. Jacobs R, Quirynen M, Bornstein MM. Neurovascular disturbances after implant surgery. Periodontology 2000. 2014 Oct;66(1):188-202.

21. Balshi SF, Wolfinger GJ, Balshi TJ A retrospective evaluation of a treatment protocol for dental implant periapical lesions: Long-term results of 39 implant apicoectomies. Int $\mathrm{J}$ Oral Maxillofac Imp 